\title{
Investment in research as a national priority
}

The first time nations made research a national priority was in the early 15 th century on the Iberian Peninsula. Spain and Portugal began an historic competition to discover an all-water route to the Indies to capture the lucrative spice trade. The two nations went about the process of discovery literally in 180 degree opposite directions. Spain commissioned Christopher Columbus on a risky mission to determine whether India could be found by heading directly west. The Portuguese headed the other way, inching east around the continent of Africa.

The Portuguese model was centralized at the national navigational institute at Sagres. Here, Prince Henry the Navigator collated the raw data from the returning caravels: latitude, longitude, ocean depths, dead reckoning landmarks and current. Slowly, the caravels crept down the western coat of Africa, overcame the nautical and psychological barrier of rounding the Horn, and slowly pushed up the eastern coast. Like the incremental nature of scientific discovery today, each new voyage built on the knowledge gleaned from the last. Then as now, accurate measurement, detailed reporting, and accurate communication were essential to the success of the enterprise.

When Vasco DiGamma reach India, the price of pepper in Venice plunged. A new route for the spice trade had been established which did not require the payment of costly tolls across the lengthy land route. Commitment to research established an Empire which would last two centuries. Then, as now, new knowledge can revolutionize the markets.

Spain was technically unsuccessful in achieving the primary objectives of its research. She did not find an all water route to India. Instead, she discovered something fundamentally more important - the New World. The economic consequences of this discovery were greater yet than monopolizing the spice trade. Then as now, research can have completely unanticipated outcomes.

The National Institutes of Health in the United States represent this nation's commitment to the importance

Rev Oncología 2000; 2: 116. of basic research. In the history of mankind, there has never been a greater, more consistent, and publicly funded investment to understand the biology of human disease. Like Columbus and DiGamma, scientists working in research laboratories and conducting clinical trials have steadily moved forward with incremental progress toward a clearly visualized goal - the prevention and cure of human disease.

In the area of cancer research, we have clearly rounded the Horn. The understanding of cancer at a basic level has brought new targets for cancer treatment into sharper focus. We now understand cancer as a genetic disease. No longer do new therapies target a single feature of the cancer cell - uncontrolled growth. Instead, new vaccine like MART-1 gp100, p53 and ras peptides are targeting the cancer cell's ability to evade immune surveillance. Anti-angiogenesis agents like endostatin, angiostatin, and Col-3 promise to inhibit the tumor's ability to make new blood vessels and convert cancer into a stable, chronic disease, devoid of the ability to metastasize. By targeting normal endothelial cells rather than tumor, drug resistance is not likely to occur with agents like endostatin.

We are now in the third year of the U.S. Congress' commitment to double the budget of the NIH over five years. The commitment could not have been better timed. When grants are funded at the 20th percentile, peer review does not work well. And when managed care makes clinical research a secondary priority, we erode the ultimate purpose of basic research: the prevention and cure of human disease.

The investment of the Congress and the Clinton Administration will prove to be wise. With the knowledge already in hand and the capacity to translate this knowledge into new diagnostic, preventative and treatment approaches, we can begin to realistically vision the cure of cancer.

A new era is at hand.

Gregory A. Curt, MD. 